\title{
The Impact of Location and Ventilation on Pool Fire in a Compartment
}

\author{
A.R. PARKES and C.M. FLEISCHMANN \\ University of Canterbury \\ Christchurch \\ New Zealand
}

\begin{abstract}
This paper describes recent experiments to investigate the effects that the location of a fire within an enclosure has upon the rate of heat release. A series of pool fire experiments in a $1 \frac{1}{2}$ domestic scale compartment using three ventilation geometries (fully open, soffit, and door), and heptane pool fires located in three evenly distributed locations within the compartment (rear, centre and front). The primary goal of this work is to the impact that the fire location within a compartment can have on the heat release rate and subsequent compartment conditions. Results indicate that the fire location and ventilation can significantly impact the heat release rate of the fire. In most cases the fire will have a larger heat release rate than under free burning conditions however, when the fire is near the opening the heat release rate is actually less than the free burning value.
\end{abstract}

KEYWORDS: compartment fires, fire growth, fire location, heat release rate, mass loss rate, pool fires, flashover

\section{INTRODUCTION}

The practicing fire engineer in today's performance based environment evaluates the life safety risk to occupant with respect to the fire conditions developing within a room. The use of fire and evacuation modelling is often employed to assess the fire conditions in conjunction with the fire protection measures provided. It should be noted however that these evaluative tools are only as accurate as the limitations of the models used and input fire scenarios assessed by the engineer.

With the advancement of computational fire modelling, the current computer models are able to provide greater accuracy with which a fire scenario can be simulated. However an increased level of analysis also requires an increased level of understanding as to requirements of the input parameters.

The common computational tool used by the practising engineer is that of a zone model due to the low cost, availability and ease of use. Zone models rely on the user to input an expected fire scenario and by default this is generally located in the centre of the input room geometry. Based upon the engineer specifying a time dependent fire growth rate using engineering judgement (typically the fire growth rates are based upon the idealised $\mathrm{t}^{2}$ fire growth rates), the output of the analysis is regarded as a 'worst case fire scenario'. Generally, corner and wall fire scenarios are neglected and other locations within the room are not expected to result in significantly different behaviour to that of the centrally located scenario. Hence location of the fire source is not deemed important and is not accounted for.

Computational Fluid Dynamic (CFD) models are less commonly used as a consultancy tool due to their cost and time consuming use. However the results from these models can 
provide significant advantages, although the model will still be bound by the user input and general scenarios as mentioned above.

Generally the factors that influence the development of a fire in an enclosure are: fuel type, enclosure geometry and properties, and ventilation. Given the use of pool fires in this study, it is recognised that compartment effects due to radiation and ventilation play as significant role in the burning rate of the pool fire. This has a considerable effect on the heat release rate and the fire dynamics within enclosures. Although the location of a fire can also have a distinct effect on the fire development, this specifically relates to wall and corner fires. Typically if a fuel package is located away from the bounding walls, air is able to be entrained into the plume from all directions. Therefore the location of a fire away from the walls is not considered a significant factor and worst case fire scenarios are developed considering fire located in the centre of an enclosure.

This paper describes recent experiments at the University of Canterbury to investigate the effect that the location of a fire within an enclosure has upon the mass loss rate and rate of heat release. A series of compartment fires using three typical ventilation geometries (fully open, soffit, and door), and heptane pool fires located in three evenly distributed locations within the compartment (rear, centre and front) are discussed and the results presented. The primary goal of this work is to demonstrate that location of the fire within a compartment can play a significant role in compartment fires.

\section{BACKGROUND}

Burning liquid fires have been studied extensively. It has long been known that the burning rate of pool fires is controlled by the heat transfer back to the surface. For pool fire sizes of interest to fire engineers, i.e., diameters greater than $0.2 \mathrm{~m}$, the heat transfer is governed by the radiation back to the surface. For pool fires with diameters between $0.2 \mathrm{~m}$ and $1 \mathrm{~m}$ the flame is considered to be optically thin whereas pool fires greater than $1 \mathrm{~m}$ diameter the flame is optically thick [1]. The burning rate for pool fires greater than $0.2 \mathrm{~m}$ can be estimated using the following semi-theoretical expression [2].

$$
\dot{\mathrm{q}}=\Delta \mathrm{h}_{\mathrm{C}} \dot{\mathrm{m}}_{\mathrm{f}}=\Delta \mathrm{h}_{\mathrm{C}} \dot{\mathrm{m}}_{\infty}^{\prime \prime}[1-\exp (-\kappa \beta \mathrm{D})] \mathrm{A}_{\mathrm{p}}
$$

For heptane in a $0.2 \mathrm{~m}$ square pan the free burning heat release rate is expected to be $100 \mathrm{~kW}$ using typical values for heptane $\left(\dot{m}_{\infty}^{\prime \prime}=0.101 \mathrm{~kg} / \mathrm{s} \cdot \mathrm{m}^{2}, \kappa \beta=1.1 \mathrm{~m}^{-1}, \Delta h_{c}=44.6 \mathrm{MW}\right)$ taken from reference [1].

A pool fire geometry represents a worse case in terms of radiation enhanced mass loss rate. The entire fuel surface sees the hot upper layer and bounding surfaces. Thomas and Bennetts, have studied large pool fires in a deep narrow compartment with different opening geometries [3]. In their study, the entire floor of the compartment was covered with fuel pans. Results highlighted the importance of ventilation geometry on the burning rate of the pools.

More complex wood cribs fuels in large narrow enclosures have been studied at BRE $[4,5]$. In the BRE study, wood cribs were placed over the entire floor of a long narrow compartment with a single vent at the opposite end of the enclosure. The importance of the fire location relative to the opening was also identified in this work as the fire ignited in the rear, spread quickly to the front of the enclosure and then spread more slowly into 
the compartment as the fuel was consumed, thus demonstrating the importance of the fire location relative to the ventilation opening.

The expected heat release rate within an enclosure sufficient to cause flashover can be calculated using the following expression derived by Babrauskas [6].

$\dot{Q}=600 A_{o} \sqrt{H_{o}}$

For the different ventilation geometries represented in this study the most severe ventilation limited case is that of the door opening of $0.4 \mathrm{~m}$ wide by $1.0 \mathrm{~m}$ high. This has an $\mathrm{Ao} \sqrt{\mathrm{Ho}}=0.4$, providing a predicted heat release rate of $240 \mathrm{~kW}$ for flashover.

For the pool fire geometry represents a worse case in terms of radiation enhanced mass loss rate. The entire fuel surface sees the hot upper layer and bounding surfaces. More complex fuels such as furniture or wood cribs will be partially shielded from the compartment environment and therefore less radiation will reach the fuel surface.

\section{EXPERIMENTAL APPARATUS AND PROCEDURE}

\section{Apparatus}

Nine experiments were conducted in a $2.4 \mathrm{~m}$ wide by $3.6 \mathrm{~m}$ long by $1.2 \mathrm{~m}$ high compartment constructed from stainless steel. Figure 1 is a sketch of the compartment showing the three pan locations, fully open ventilation, and notable instrumentation. The walls, ceiling and floor of the compartment were lined with two layers of $10 \mathrm{~mm}$ ceramic fibre board. For visual observations, five windows were located on one side of the compartment, four at lower half of the compartment with the fifth located at the upper level near at the front of the room.

Ventilation into the compartment was designed to be easily modified using panel construction to enable the ventilation geometry to be changed from fully open, to a soffit, and to a door. These panels when connected to the compartment are also lined with two layers of $10 \mathrm{~mm}$ ceramic fibre board. The dimensions of the various ventilation geometries are as follow:

1. Full: $2.4 \mathrm{~m}$ wide by $1.2 \mathrm{~m}$ high $(\mathrm{Ao} \sqrt{\mathrm{Ho}}=3.15)$

2. Soffit: $2.4 \mathrm{~m}$ wide by $1.0 \mathrm{~m}$ high $(\mathrm{Ao} \sqrt{\mathrm{Ho}}=2.4)$

3. Door: $0.4 \mathrm{~m}$ wide by $1.0 \mathrm{~m}$ high $(\mathrm{Ao} \sqrt{\mathrm{Ho}}=0.4)$

Heptane pool fires were used in all experiments, with a $200 \mathrm{~mm}$ square pan $50 \mathrm{~mm}$ high. The perimeter of the pan was insulated with $20 \mathrm{~mm}$ thick ceramic fibre board. The pan is able to be positioned in three 3 different locations within the room for every corresponding change in ventilation opening. These locations are as follow (based upon pan centreline dimensions);

a) Rear location: The pan in the rear position was located $3.0 \mathrm{~m}$ from the front of the compartment.

b) Centre location: The pan in the centre location position was located $1.8 \mathrm{~m}$ from the front of the compartment. 
c) Front location: The pan in the front location position was located $0.6 \mathrm{~m}$ from the front of the compartment.

Heptane fuel is pumped from 40-litre pre fabricated stainless steel fuel tanks using a tubing pump connected to individual header tanks. From the header tank the pan was gravity fed allowing a constant fuel surface height. Ignition was by a series of sparkplug electrodes connected to two 15000 volt transformers.

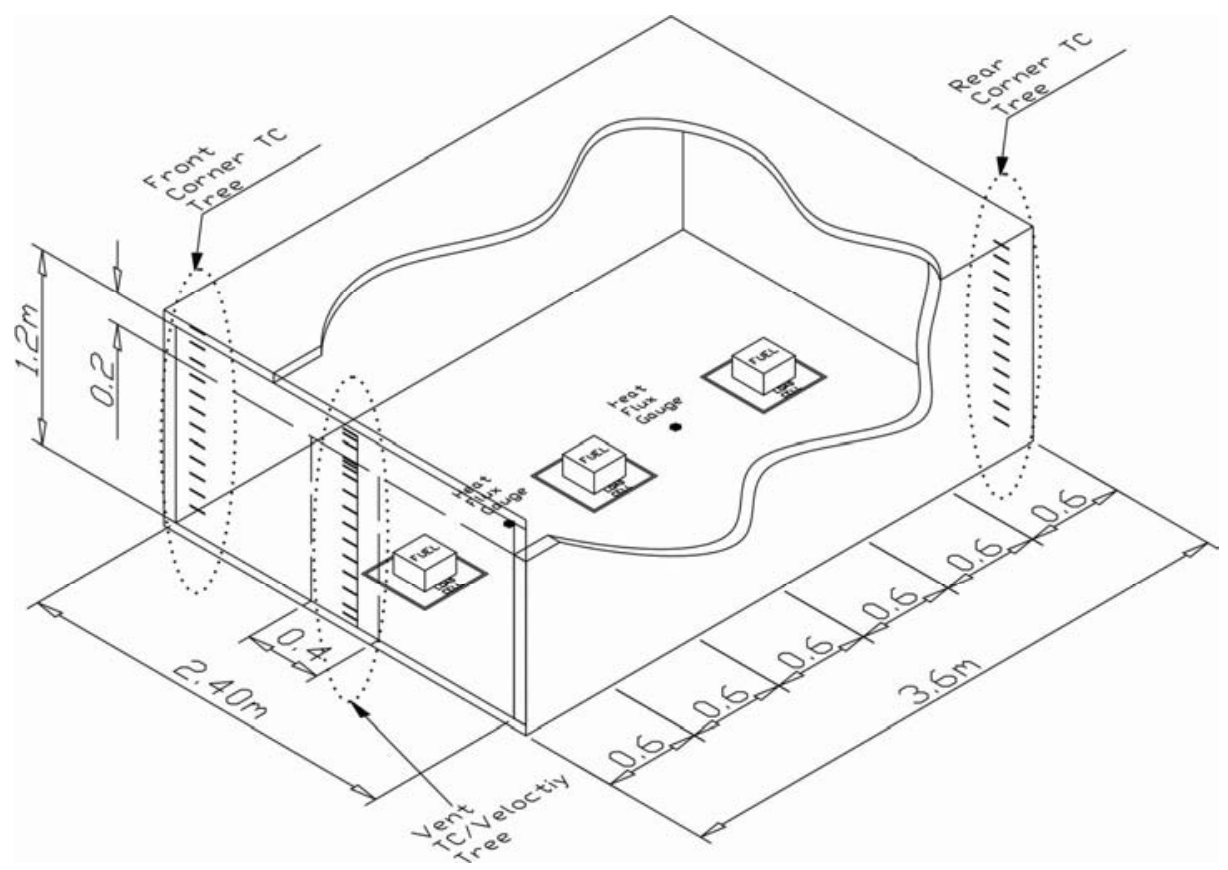

Fig. 1. Sketch of the experimental compartment showing all three pool fire locations, fully open ventilation condition and relevant instrumentation.

\section{Instrumentation}

Compartment Temperatures: To measure the compartment gas temperatures, vertical thermocouple trees were placed at the front and rear of the enclosure (see Fig. 1). Two sets of 15, $1.6 \mathrm{~mm}$ diameter type $\mathrm{K}$ thermocouples were used and positioned at spacings of generally $100 \mathrm{~mm}$ vertically between the floor and ceiling. To avoid effects from the boundary layer, the thermocouples were placed $150 \mathrm{~mm}$ off the rear wall, $100 \mathrm{~mm}$ off the side walls, and $25 \mathrm{~mm}$ from the floor/roof.

Vent Temperatures/Pressures: A thermocouple tree was placed within the vent to record the vent temperatures. 14, $1.6 \mathrm{~mm}$ diameter type $\mathrm{K}$ thermocouples at a spacing of $100 \mathrm{~mm}$ were used, with this being reduced to 12 when the soffit/door geometry was used. $10 \mathrm{Bi}$-directional probes connected to pressure transducers with a pressure range of 0-25 Pa were also placed in the vent for measurements of vent velocities.

Heat Flux: Two Gardon type heat flux gauges were placed between each of the separate pan locations e.g., $600 \mathrm{~mm}$ from the centre of each pan. The heat flux gauge at location 1 is $1800 \mathrm{~mm}$ from the front opening (between the rear and centre pans) and location 2 is 
$1200 \mathrm{~mm}$ from the front opening (between the centre and front pans). These were used to measure the radiation heat flux at the floor during each experiment.

Mass Loss: The mass loss of the fuel was recorded on a load cell upon which the fuel tanks sit.

Heat Release Rate: The heat release rate from each experiment was measured using oxygen depletion calorimetery and included $\mathrm{O}_{2}, \mathrm{CO}_{2}$, and $\mathrm{CO}$ species measurements. The extraction system had a maximum flow rate of $4 \mathrm{~m}^{3} / \mathrm{s}$.

Data Acquisition: A Universal Data Logging (UDL) system developed at the University of Canterbury is used to log voltages from the above instrumentation through software and hardware interfaces. The hardware consists of serial boxes for each different sensing device which is then calibrated with the UDL programme and an associated calibration and offset factors. The sampling rate for the UDL program was 1 sample per second using a Pentium P4 computer.

\section{Procedure}

Ten experiments were conducted in this series including one experiment of a single pan in the open under quiescent conditions to provide a base case for comparison. Table 1 summarizes the ventilation geometry and pan locations for the nine compartment experiments.

Table 1. Experimental Matrix for the nine compartment experiments showing the pan location and ventilation geometry.

\begin{tabular}{|c|c|c|c|c|}
\hline & \multicolumn{3}{|c|}{ Ventilation Geometry } \\
\hline & & Full & Soffit & Door \\
\hline & & & $0.2 \mathrm{~m}$ & $\begin{array}{c}0.4 \mathrm{~m} \times 1.0 \mathrm{~m} \text { high } \\
(0.2 \mathrm{~m} \text { soffit })\end{array}$ \\
\hline \multirow{3}{*}{ لَّ } & Rear pan & 1 & 1 & 1 \\
\hline & Centre Pan & 1 & 1 & 1 \\
\hline & Front Pan & 1 & 1 & 1 \\
\hline
\end{tabular}

Each experiment involved calibration of the oxygen depletion calorimetery system before commencement. A three minute baseline is also taken to record the initial conditions, with ignition of the pan at three minutes. Each experiment was allowed to run for a total duration after ignition of at least 60 minutes.

\section{EXPERIMENTAL RESULTS}

\section{Summary}

The results of the 10 experiments are summarised in Table 2. Column 1 gives the location of the pan within the compartment (Free - free-burning in open, Rear - $3.0 \mathrm{~m}$ from opening, Centre - $1.8 \mathrm{~m}$ from opening, Front $-0.6 \mathrm{~m}$ from front). Column 2 is the ventilation configuration (Full $-1.2 \mathrm{~m}$ by $2.4 \mathrm{~m}$ wall fully open, Soffit $-2.4 \mathrm{~m}$ wide by $1.0 \mathrm{~m}$ high, Door $-0.4 \mathrm{~m}$ wide by $1.0 \mathrm{~m}$ high). Column $3 \& 4$ is the total heat release rate and total mass loss, respectively, during the fully developed phase of burning 900 to 3600 seconds. Column $5 \& 6$ is the mass loss rate and effective heat of combustion, respectively, calculated from column $3 \& 4$. Columns $7-9$ are the layer height, upper layer temperature, and lower layer temperature based on maximum slope of the 
temperature profile at TC tree \#2 in the corner nearest the opening. Column 10 and 11 are the average heat flux measurements $1.2 \mathrm{~m}$ from the front opening and $1.2 \mathrm{~m}$ from the rear wall, respectively, averaged over 3000 to 3600 seconds. Column 12 and 13 is the mass loss rate and heat release rate, respectively, averaged over the 3000 to 3600 seconds.

Table 2. Summary of the data from all 9 experiments and the free-burning pool fire.

\begin{tabular}{|c|c|c|c|c|c|c|c|c|c|c|c|}
\hline $\begin{array}{c}\text { Pan } \\
\text { Location }\end{array}$ & \begin{tabular}{|c|} 
Vent \\
Config.
\end{tabular} & $\left|\begin{array}{l}\text { Total HRR 900 } \\
3600 \text { sec (MJ) }\end{array}\right|$ & $\begin{array}{l}\text { Mass Loss } \\
(\mathrm{kg})\end{array}$ & $\underset{(\mathrm{kJ} / \mathrm{kg})}{\Delta \mathrm{Hc}}$ & $\begin{array}{c}\text { Layer } \\
\text { Height, } \mathrm{H}_{\mathrm{L}} \\
@ 3600 \\
\sec (\mathrm{m})\end{array}$ & \begin{tabular}{|c|}
$\mathbf{T}_{\text {Ave }}$ Upper \\
Layer @ \\
$3600 \mathrm{sec}$ \\
$\left({ }^{\circ} \mathrm{C}\right)$
\end{tabular} & $\begin{array}{c}\mathbf{T}_{\text {Ave }} \text { Lower } \\
\text { Layer @ } \\
3600 \mathrm{sec} \\
\left({ }^{\circ} \mathrm{C}\right)\end{array}$ & $\begin{array}{c}\text { Ave. Heat } \\
\text { Flux } \# 1 \\
3000-3600 \\
\sec \left(\mathrm{kW} / \mathrm{m}^{2}\right)\end{array}$ & $\begin{array}{c}\text { Ave. Heat } \\
\text { Flux } \# 2 \\
3000-3600 \\
\sec \left(\mathrm{kW} / \mathrm{m}^{2}\right)\end{array}$ & $\begin{array}{l}\text { Ave. Mass } \\
\text { Loss Rate } \\
3000-3600 \\
\text { sec }(\mathrm{kg} / \mathrm{s})\end{array}$ & $\begin{array}{c}\text { Ave. HRR } \\
3000-3600 \\
\text { sec (kW) }\end{array}$ \\
\hline Open & & 231 & 5.1 & 45486 & & & & & & 0.0019 & 86.6 \\
\hline \multirow[t]{3}{*}{ Rear } & Full & 261 & 6.4 & 40892 & 1000 & 129 & 30 & 4.5 & 2.4 & 0.0025 & 101.6 \\
\hline & Soffit & 245 & 6.4 & 38858 & 700 & 129 & 23 & 5.1 & 2.8 & 0.0026 & 95.6 \\
\hline & Door & 572 & 13.6 & 41957 & 300 & 478 & 77 & 60.4 & 41.5 & 0.0064 & 270.2 \\
\hline \multirow[t]{3}{*}{ Centre } & Full & 224 & 5.1 & 44706 & 1000 & 109 & 29 & 9.0 & 3.2 & 0.0019 & 82.3 \\
\hline & Soffit & 245 & 5.2 & 46840 & 700 & 119 & 24 & 11.5 & 3.9 & 0.0020 & 95.6 \\
\hline & Door & 491 & 11.5 & 42371 & 400 & 448 & 109 & 70.6 & 45.9 & 0.0048 & 208.4 \\
\hline \multirow[t]{3}{*}{ Front } & Full & 237 & 5.5 & 43414 & 1000 & 128 & 50 & 1.8 & 9.0 & 0.0019 & 80.5 \\
\hline & Soffit & 245 & 5.6 & 43359 & 800 & 151 & 45 & 2.5 & 9.3 & 0.0022 & 93.9 \\
\hline & Door & 147 & 3.4 & 43128 & 400 & 183 & 28 & 3.3 & 12.8 & 0.0013 & 55.0 \\
\hline
\end{tabular}

Figure 2 compares the heat release rate histories for the three different pan locations with the simulated door opening $0.4 \mathrm{~m}$ wide and $1.0 \mathrm{~m}$ high. The plot also includes the freeburning pool fire heat release rate history for further comparison. The free-burning fire shows a steady heat release rate of $86 \mathrm{~kW}$ after the initial growth phase of approximately 3 minutes. This is $15 \%$ lower than the predicted value given in Eq. 1 above. This reduction is believed to be due to the constant fuel surface height and insulated pan walls. Both the rear and centre pan experiments with the door vent geometry show significant enhancement to the fire due to radiation feedback from the compartment. Table 2 shows the average heat release rate, after one hour, of $208 \mathrm{~kW}$ for the centre location and $270 \mathrm{~kW}$ when the pan was placed in the rear of the compartment which is a $139 \%$ and $210 \%$ increase respectively over the free burning heat release rate. These values when compared with Eq. 2 above show that the placement of the pan from the centre to the rear causes a transition from pre-flashover to the predicted post-flashover phase. This is in sharp contrast to the pan placed near the front opening in which the fire has an average heat release rate after 60 minutes of only $55 \mathrm{~kW}$ which represents a 37\% decrease compared to the free-burning value. This reduction in heat release rate when compared to the free-burning case is a result of the flame being forced over by the incoming air through the vent. Figure 3 shows a set photographs one for each pan location and vent configuration. Figures 3A-C shows the flame shape for the door vent with the pan at the front, centre, and rear, respectively. The front pan location (Fig. 3A) had the most severe tilt and was significant enough to reduce the radiation feedback to the fuel surface. For the centre pan location the flame (Fig. 3B) was also blown over but not as severely as the front location and for the rear pan location the flame was blown horizontally to the rear and up vertically up the wall (Fig. 3C). It can also be seen in Figs. 3B \& C, that there is significant burning around the base of each of the pans. 


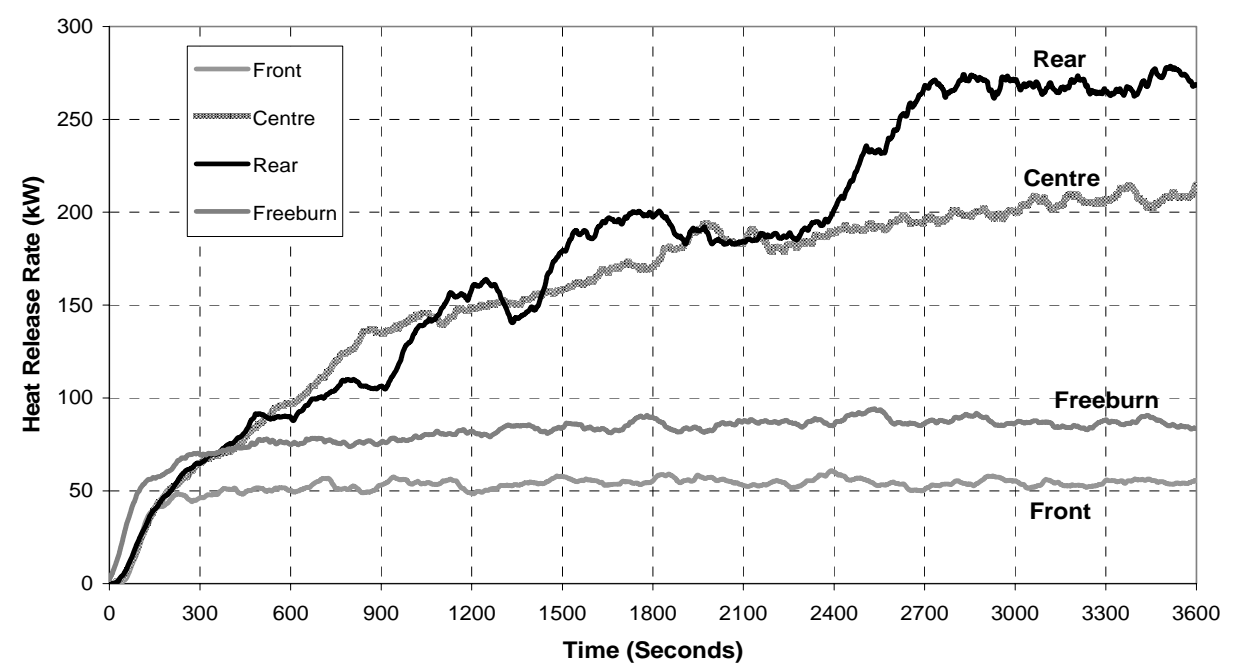

Fig. 2. Comparison of the heat release rate histories for the each of the three pan locations with a single door vent $0.4 \mathrm{~m}$ wide and $1.0 \mathrm{~m}$ height along with the free-burning pool.
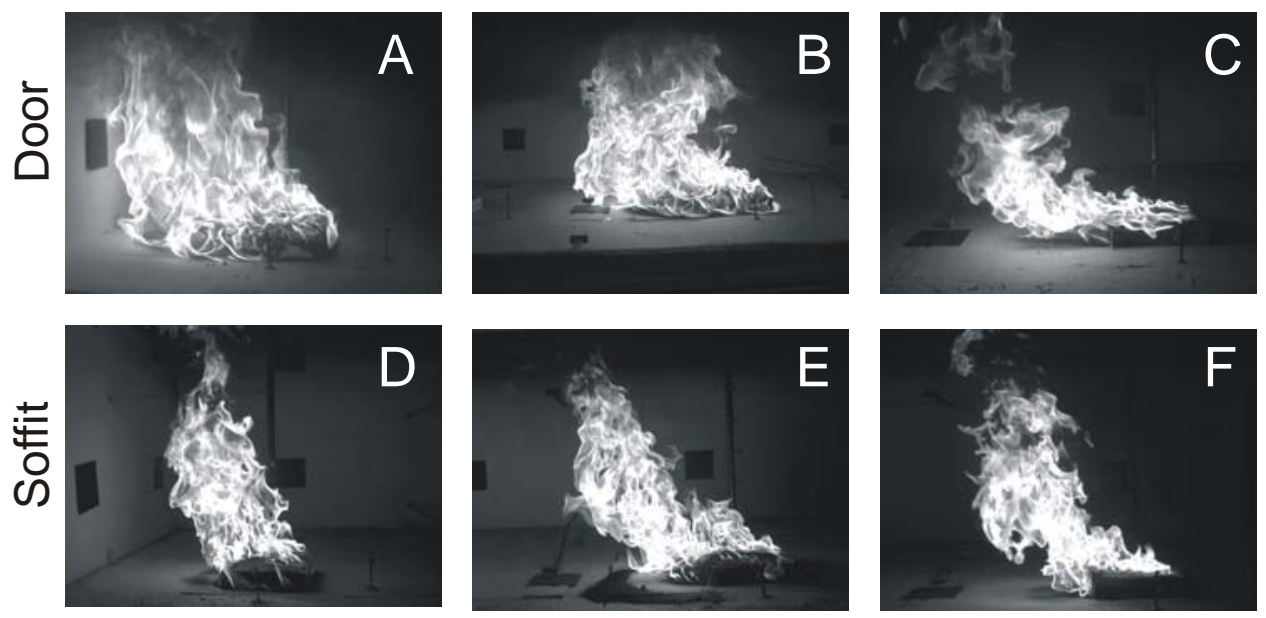

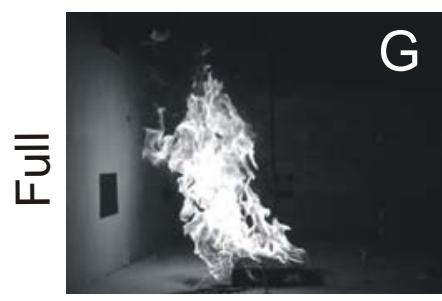

Rear

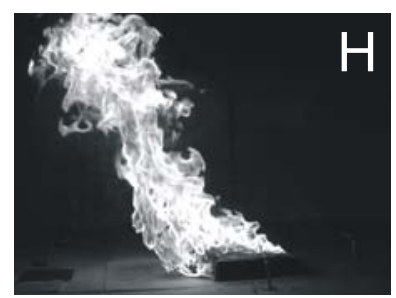

Centre

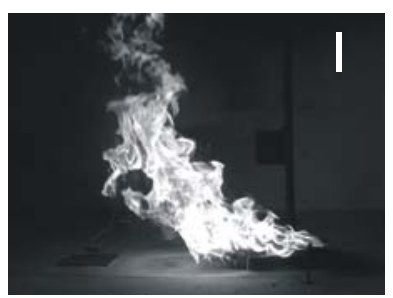

Front

Fig. 3. Photographs taken for each pan location showing the flame structure.

Figure 4 compares the heat release rate histories for the three different ventilation openings with the fire in the rear of the compartment. The plot also includes the freeburning pool fire heat release rate history for further comparison. For the full and soffit openings the heat release rate is nearly identical to the open case, however, for the door 
opening the fire grows to $200 \mathrm{~kW}$ and becomes relatively steady before reaching flashover after $2400 \mathrm{~s}$ when the heat release increases to $270 \mathrm{~kW}$. Table 2 shows the average heat release rate after one hour of $102 \mathrm{~kW}$ for the full opening and $96 \mathrm{~kW}$ for the soffit which is a $17 \%$ and $10 \%$ increase respectively over the freeburn case. Thus indicating there was only minor radiation enhancement with in the compartment. This is in stark contrast to the door opening case described above which shows significant enhancement to the fire due to radiation feedback from the compartment and an average heat release rate of $270 \mathrm{~kW}$.

Figure 3A, D, \& G are photographs of the pool fire showing the flame shape for the door, soffit and full vents, respectively, with the pan in the rear of the compartment. The full vent (Fig. 3G) and soffit vent (Fig. 3D) had relatively minor tilt, but the door vent (Fig. 3A) show tilting and significant burning around the base of the pan such that the flame is in contact with the wall.

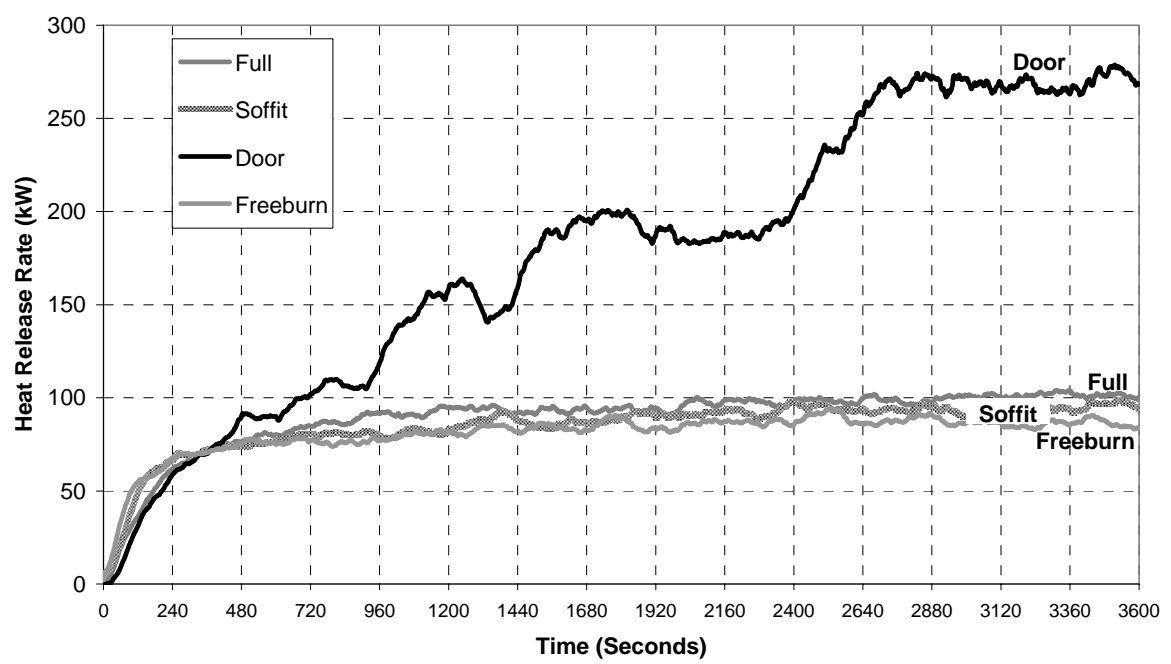

Fig. 4. Comparison of the heat release rate histories for the pan in the rear of the compartment for each of the three ventilation openings along with the freeburn pool.

Figures 5 and 6 compare the average aspirated thermocouple temperatures in the ceiling jet and Gardon gauge heat flux history measurements with the fire at the rear of the compartment. It can be seen that reduction in ventilation provided by the door vent geometry provides significant radiation enhancement to the fire from the compartment in comparison with the full and soffit vents. In both the full and soffit geometries the ceiling jet temperatures do not exceed $300^{\circ} \mathrm{C}$ wile the door geometry temperatures approach $800^{\circ} \mathrm{C}$. Table 2 also shows that the conditions within the compartment are representative of a post-flashover situation considering typical post-flashover conditions of temperatures $>600{ }^{\circ} \mathrm{C}[6]$ and heat flux values at the floor $>20 \mathrm{~kW} / \mathrm{m}^{2}$ [7]. 


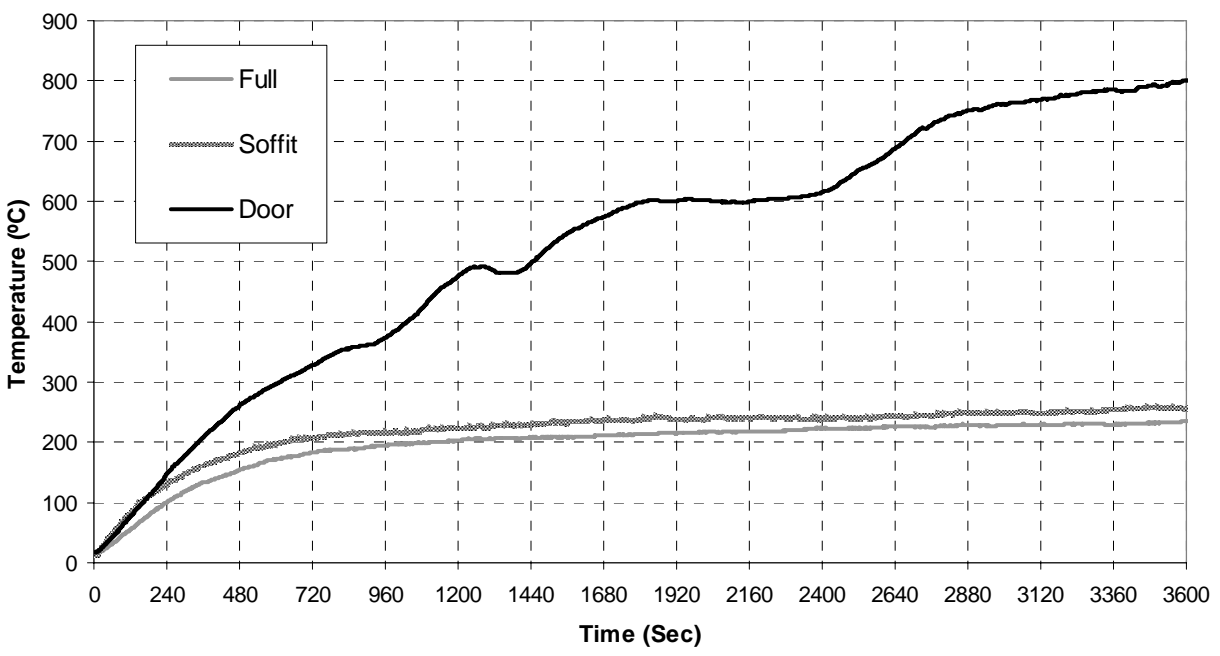

Fig. 5. Average temperature histories for the two aspirated thermocouple $25 \mathrm{~mm}$ below ceiling located $1.2 \mathrm{~m}$ from the front opening and $1.2 \mathrm{~m}$ from rear wall of the compartment for each of the three ventilation openings.

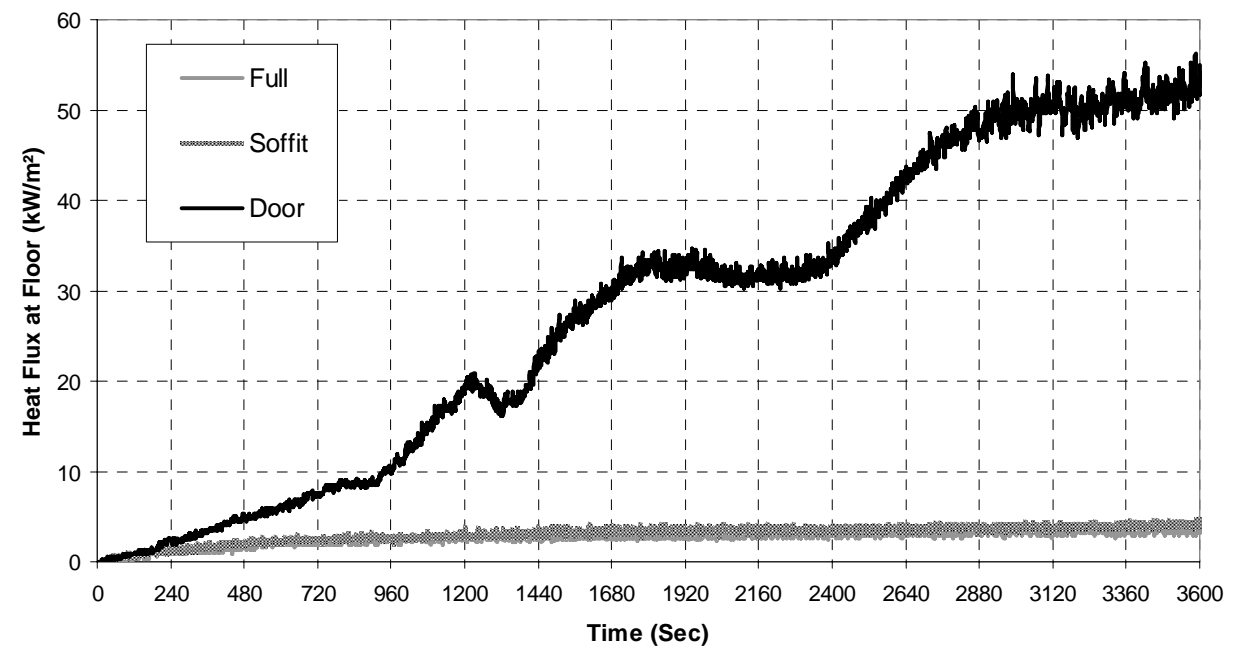

Fig. 6. Average heat flux histories received at floor level, $1.2 \mathrm{~m}$ from the front opening and $1.2 \mathrm{~m}$ from rear wall of the compartment for each of the three ventilation openings.

Figure 7 shows the temperature profile from the thermocouple tree located in the corner closest to the ventilation opening 60 minutes after ignition (see Fig. 1). The profile for the pan in the rear of the compartment for the full opening (Full-Rear) show a typical profile expected for a ceiling jet flow with the high temperatures near the ceiling and a rapid drop in temperature moving toward the floor. This profile was consistent for all of the pan locations with the full vent opening. For the rear pan with the soffit opening (SoffitRear) the profile is the traditional two layer pre-flashover profile. This was also consistent for all the other pan locations with the soffit ventilation opening with the average upper layer temperature being on the order of $200^{\circ} \mathrm{C}$, as seen in Table 2. For the 
door vent, the profiles were less consistent or predictable. The front pan door opening experiment (Door-Front) the profile is a typical two layer pre-flashover profile with an upper layer temperature of $240^{\circ} \mathrm{C}$. However, when the same pan is moved to the rear of the compartment (Door-Rear) the temperature profile is more uniform from floor to ceiling as expected in a fully a developed post-flashover fire. In this case the average temperature was $660^{\circ} \mathrm{C}$ well within the expected post-flashover temperatures [7]. For the fire in the centre of the compartment with the door opening (Door-Centre) there is a more transitional profile between pre- and post- flashover with an average upper layer temperature of $600^{\circ} \mathrm{C}$ but reducing to less than $450^{\circ} \mathrm{C}$ near the floor.

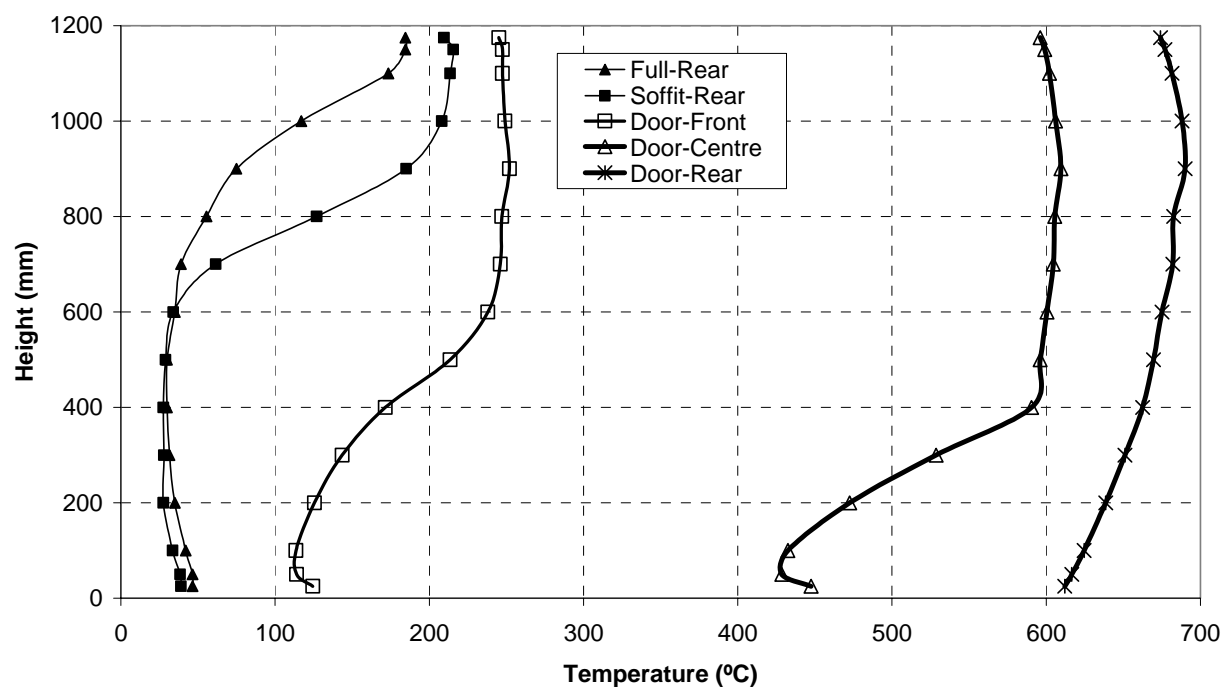

Fig. 7. Temperature profiles at the thermocouple tree in the compartment corner closest to the vent from the rear pan experiments for the full, soffit, and door ventilation openings as well as the door vent experiments for the pool fire at the centre and front locations, 3600 seconds after ignition.

Figure 8 shows the velocity profile for the bi-directional probes located in the centre of the vent opening (see Fig. 1) 3600 seconds after ignition.

In the rear pan experiment for both the full and soffit opening the velocities near the floor are less than $0.2 \mathrm{~m} / \mathrm{s}$ which caused the flame in the pan to tip approximately $30^{\circ}$ off the vertical axis as seen in Figs. 3F\&I. However, for the door experiments the velocities were much higher ranging from $0.37 \mathrm{~m} / \mathrm{s}$ for the front location to $0.5 \mathrm{~m} / \mathrm{s}$ for the rear location. The affect on the flame shape can be seen in Fig. 3A-C which shows the flame blown over significantly enough that the flame is in contact with the floor on the leeward side of the pan. 


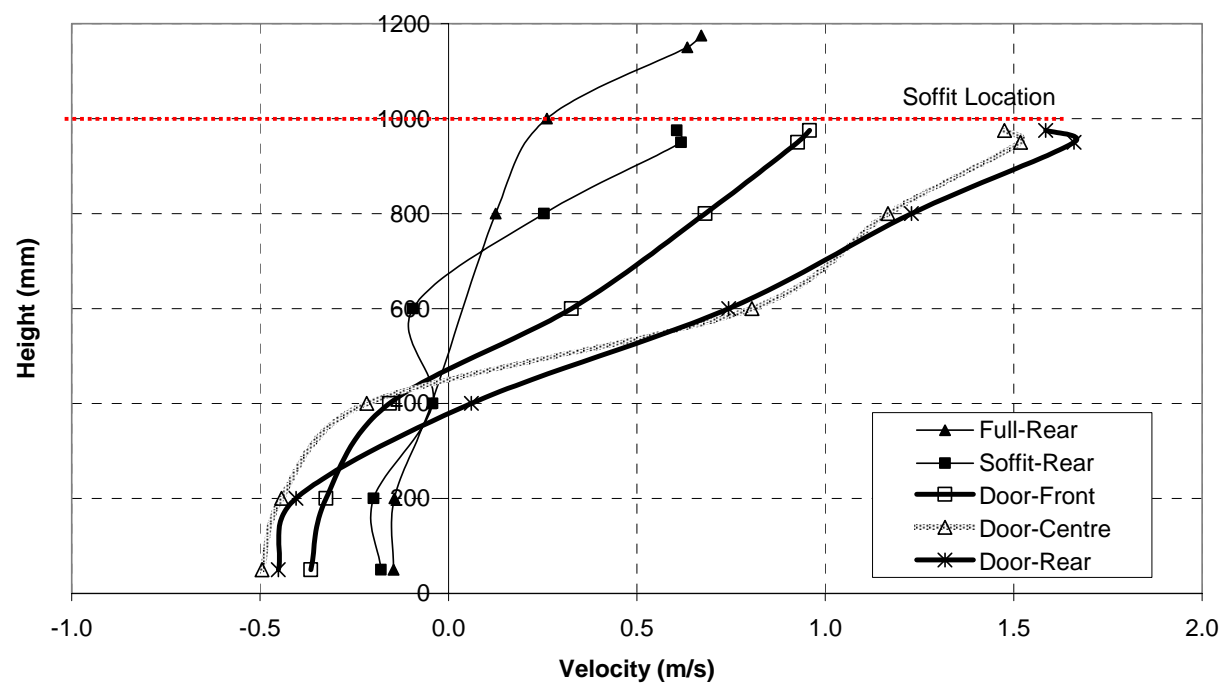

Fig. 8. Velocity profiles at the bi-directional probes in the centre of the vent opening from the rear pan experiments for the full, soffit, and door ventilation openings as well as the door vent experiments for the pool fire at the centre and front locations, 60 minutes after ignition.

\section{CONCLUSIONS}

- The results of this research clearly show that the location of the fire can have a pronounced effect on pool fires. This can be seen in the experiments with the door vent geometry, where a transitional phase between a pre-flashover fire and a post flashover fire occurs when the pan is moved progressively from the front to the rear of the compartment.

- The heat release rate for the pool fire is a function of the fire location and can be significantly greater than the predicted free burning rate and even greater than the maximum free burning rate for an optically thick pool fire.

- The shape of the flame is greatly impacted by the velocity through the vent and can even be pushed over by the incoming airflow such that the flame is in contact with the floor on the leeward side of the pan. In some cases the incoming air can actually reduce the heat release rate below the free-burning heat release rate.

\section{FUTURE RESEARCH}

- Further research should include multiple fires in multiple locations to assess the impact on the compartment environment when compared to a single fire of equal surface area.

- Additional work is need using different size vents over a range of opening factors in order to further quantify the heat release rate versus ventilation factor.

- More experimental work is required to quantify the effect of fire location when the fire is not located along the centreline of the ventilation opening including along sidewalls and in corners. 
- The results given here should be modelled in field models such as FDS to validate the model for use in fire location studies such as this. Many of the recommendations given above could be tested numerically to reduce the size of the experimental work required.

\section{ACKNOWLEDGEMENTS}

The authors would like to acknowledge the financial support provided by the New Zealand Fire Service Commission and the Foundation of Research Science and Technology (FRST).

\section{REFERENCES}

[1] Babrauskas, V, "Heat Release Rates," The SFPE Handbook of Fire Protection Engineering, Section 3/Chapter 1, 3rd edition, 2002.

[2] Babrauskas, V, "Estimating Large Pool Fire Burning Rates,” Fire Technology, 19, pp. 251, (1983).

[3] Thomas, I.R., and Bennetts, ID., "Fires in Enclosures with Single Ventilation Openings - Comparison of Long and Wide Enclosures," Fire Safety Science Proceedings of the Sixth International Symposium, pp. 941-952, 1999.

[4] Kirby, B.R., Wainman, D.E., Tomlinson, L.N., Kay, T.R. and Peacock, B.N., "Natural Fires in Large Scale Compartments," A British Steel Technical, Fire Research Station Collaborative Project, BSC, 1994.

[5] Cooke, G.M.E., "Tests to Determine the Behaviour of Fully Developed Natural Fires in a Large Compartment,” Fire Note 4, BRE, 1998.

[6] Walton, W.D, and Thomas, P.H, "Estimating Temperatures in Compartment Fires," The SFPE Handbook of Fire Protection Engineering, Section 3/Chapter 6, 3rd edition, 2002.

[7] Drysdale, D, An Introduction to Fire Dynamics, 2nd Edition, John Wiley \& Sons, New York, 1998. 